\title{
A Brief Discussion and Application of Interpretative Phenomenological Analysis in the Field of Health Science and Public Health
}

\author{
Tang, Kai Hong \\ Independent Scholar \\ Macau, Macau China \\ E-mail: samtangkh@yahoo.com.hk \\ Dos Santos, Luis Miguel (Corresponding author) \\ Macau Customs Service \\ Customs Training Center \\ Macau, Macau China \\ E-mail: luismigueldossantos@yahoo.com
}

Received: July 3, 2017 Accepted: August 14, 2017 Published: August 16, 2017

doi:10.5296/ijld.v7i3.11494 URL: https://doi.org/10.5296/ijld.v7i3.11494

\begin{abstract}
For a significantly long time, the field of health science and public health has relied considerably on quantitative and experimental evidence to support knowledge. Researchers in the field of social science and public health promotion advocate that qualitative research methodologies and IPA could be a useful tool to understand the inner world and perception for patients with particular illness and background. Unlike quantitative research studies, qualitative research studies do not seek statistical and experimental answers for client healing and operational activities but how and why illness influences the life of patients. The purpose of qualitative research study with a particular lens of interpretative phenomenological analysis (IPA) tends to describe a certain phenomenon or social problem by explaining the subject of study. The purpose of this study is to introduce the applications of IPA and summarize the two literature reviews with the application of IPA in the fields of nursing education and public health. The results of this study aim to provide a guideline for potential public health and
\end{abstract}




\section{Macrothink}

International Journal of Learning and Development

ISSN 2164-4063 2017, Vol. 7, No. 3

nursing educators to employ IPA and other related qualitative research methodologies to capture and reform the current teaching curriculum and the rapidly changing society in the health science field.

Keywords: Health science, interpretative phenomenological analysis, public health, qualitative 


\section{Macrothink}

\section{Introduction}

This study discusses the applications of interpretative phenomenological analysis (IPA) in the academic fields of health science and public health. As a general trend, studies on health science and nursing education rely mostly on large-size quantitative research methods and statistical analysis. However, qualitative research and life-story-oriented methodologies may not be very popular in this particular field (Melia, 1982). Thus, to understand the perspectives and conceptions of cultural and behavioral activities of clients and individuals, qualitative research analysis should be employed.

The purpose of this study is to introduce the applications of IPA and summarize the two literature reviews with the application of IPA in the fields of nursing education and public health. The results of this study aim to provide a guideline for potential public health and nursing educators to employ IPA and other related qualitative research methodologies to capture and reform the current teaching curriculum and the rapidly changing society in the health science field. As this is a literature-based review, no empirical research reports and findings are stated. However, meaningful and useful summaries for the application of qualitative research method and IPA methodology are listed.

\section{Background of IPA}

The following section provides brief historical and conceptual backgrounds of IPA as a qualitative research method. IPA is a qualitative research method. In social science research fields, two major research methodologies are used, namely qualitative research methodology and quantitative research methodology. According to Creswell (2007), these methods share many common characteristics but have significant differences. In short, qualitative research methods pertain to "how people interpret their experience, how they construct their worlds, and what meaning they attribute to their experience" (Merriam, 2009, p.5). Five significant characteristics of qualitative research methodology are (Creswell, 2007, p. 16):

1) Exploring a problem and developing a detailed understanding of a central phenomenon;

2) Having the literature review play minor roles but justify the problem;

3) Stating the purpose and research questions in a general and broad way so as to the participants' experience;

4) Collecting data based on words from a small number of individuals so that the participants' views are obtained;

5) Analyzing the data for description and themes using text analysis and interpreting the larger meaning of the findings; and

6) Writing the report using flexible, emerging structures and evaluative criteria, and including the researchers' subjective reflexivity and bias (Creswell, 2007, p. 16).

For example, rather than finding out how many people in New York City deal with obesity, which could be done through large scale questionnaire and survey, qualitative researchers tend to be more interested in the live experience of obese people and how they describe their obesity 
experience in New York City. Research on the understanding of the sense-making process, perspectives, opinions, and lived stories of participants is called qualitative research.

IPA was developed by Jonathan Smith, a well-known British psychologist at the University of London (Smith, Harre, \& Van Langenhove, 1995). IPA aims to understand a person's cognitive and psychological development as a combination of their lived stories, thinking and emotional perspectives. The three major principles of IPA include 1) phenomenology, 2) hermeneutics, and 3) idiography. IPA is an integrated methodology that allows scholars to develop an understanding of the background and inner world of participants, which are grounded and are yet to be established beyond their own understanding, sense, perspective, and conceptualization (Smith \& Osborn, 2003).

Unlike traditional phenomenological study, IPA researchers understand that the facial expressions, emotional behaviors, speech tones, and eye movements of participants are connected to a particular experience. Therefore, IPA researchers should have the ability to interpret such mental and emotional states from participants to understand the stories behind the stage (Smith \& Osborn, 2003).

After the announcement of IPA, a large number of studies in the field of social science, education, and health science have employed the application of IPA to collect meaningful data and perspectives from participants (Smith, Flower, \& Larkin, 2009). The creation of IPA was rooted in psychology and phenomenology, which was connected with Husserl's purpose to construct a research point of view in consciousness with focus on hermeneutics. The targeted research groups of IPA are people. Another targeted point of IPA is human interaction. IPA researchers believe that opinions and information of participants have an interpretative concept. Through careful research process, the researchers are allowed to access the cognitive understanding and lived stories of participants (Smith \& Osborn, 2003).

Symbolic interactionism is one of the philosophical foundations of IPA. This idea points out that potential analysis should allow researchers and readers to interpret the meaning-making and sense-making processes of the participants (Smith, 1997). By contrast, phenomenology is one of the philosophical foundations of IPA. This idea is developed from Edmund Husserl's notion of hermeneutics (the theory of interpretation). Based on the characteristics of hermeneutics, the understanding of the interpretation of the inner world of individuals and participants and how they interpret their lifeworld would be the key purposes. With the combination of both methodologies, IPA aims to understand the interest of participants on their lived experiences with interpretations of their sense-making processes (Smith \& Osborn, 2003).

In actuality, IPA engages with a double-hermeneutic approach. The role of the researchers is to make sense of the participants, who also attempt to make sense of their lived experiences. To assist the participants in understanding their lived experience and sense-making processes, the researchers may take two roles within the research. First, researchers may enter the world of the participants and attempt to use the participant role in understanding the experience. Second, in actuality, however, the researchers would never be the participants. All available information are given by the participants. Therefore, participant reporting should be on the first line, and 
researcher understanding should be on the second line. Moreover, the researchers should put themselves into the participant shoes to gather the most appropriate information (Smith, Flower, \& Larkin, 2009).

In summary, IPA and general phenomenology are similar to each other but have significant differences in between. General phenomenology tends to seek answers to the common structure of an instance as an experience. However, IPA tends to seek answer on personal understanding, perspective, and sense making in a targeted situation for a small group of people who share a lived experience (Smith, Flower, \& Larkin, 2009).

\section{Sample Size of IPA}

Unlike other quantitative research methodologies, qualitative research studies aim to understand the behaviors of particular groups of participants in a manageable population. In short, qualitative research typically requires smaller sample size than quantitative research. In general, no fixed rules on how the sample should be examined are used. For example, Morse (1994) suggested that an ethnographic study and grounded theory study should invite a sample size of 30-50 participants. However, Creswell (2007) suggested that grounded theory should invite only 20-30 participants as an ideal sample group size. For phenomenological study, Creswell (2007) suggested 5-25 as an ideal sample group size. However, Morse (1994) suggested at least six participants as the ideal sample group size. In the case of IPA, researchers do not have a unified suggestion of how many participants should be invited. However, a sample group of 1-10 should be appropriate because IPA tends to collect a small size of sample group instead of a large-size phenomenon. According to Smith and Osborne (2003), IPA does not have a fixed rule on the appropriate number of participants. However, the authors suggested that "IPA studies are conducted on a small sample size. The detailed case-by-case analysis of individual transcripts takes a long time, and the aim of the study is to say something in detail about the perceptions and understandings of this particular group rather than prematurely make more general claims" (p. 55). Aside from the description of Smith et al. (2003), other academic studies employed with IPA usually invited participants with a smaller sample size (Dos Santos, 2016; Millward, 2006; Symeonides \& Childs, 2015).

In summary, unlike other traditional qualitative research methodologies with more than 30 years of applicable experience, the applications of IPA are still in the development stage. For the sample size of participants, most IPA researchers still do not have a universal standard. However, based on the well-established IPA studies in the current academic database, most scholars tend to employ no more than 10 participants to collect effective, rich, and meaningful in-depth data information.

\section{Debate on the Applications of IPA}

For more than 30 years, debates on the employment of qualitative research methods, particularly small size sampling, have always existed in the academic field (Bryman, 1984; Carr, 1994). First, unlike quantitative research studies, qualitative research studies do not seek statistical and experimental answers for client healing and operational activities in the field of health science and public health. For example, the application of IPA in public health and 
community health education tends to seek understanding on the living difficulties of HIV/AIDS carriers and their experience in living in an urban city. Consequently, research findings could contribute to the public health and community health education and to potential improvements of the urban city. In fact, the purpose of qualitative research study with a particular lens of IPA tends to describe a certain phenomenon or social problem by explaining the subject of study (Cormack, 1991).

\subsection{Historical Preference of Quantitative Research Method}

For a significantly long time, the field of health science and public health has relied considerably on quantitative and experimental evidence to support knowledge. According to Melia (1982), health science practitioners are trained to study and read statistical and experimental textbooks and are required to undergo professional training. Therefore, most readers in this particular field tend to enjoy these types of reading. In fact, quantitative methods usually attempt to seek scientific answers and solve the hypothesis. This information is called hard data. By contrast, qualitative research methods usually seek to answer "how" and "why" questions instead of answering the hypothesis for a problem. Therefore, the scopes and purposes of both research methodologies serve different groups of readers within the particular fields (Corner, 1991).

Moreover, according to Benoliel (1984), before the 1980s, most academic studies within the health science and public health tended to be quantitative studies. As Melia (1982) mentioned, most practitioners in the fields were trained to be quantitative readers. Therefore, even today, a large number of practitioners still consider qualitative studies to have a lower status. However, Smith et al. (1997) argued that health psychology and illness researchers could benefit from understanding patient behaviors under the IPA research method. Within this literature, Smith et al. (1997) employed the IPA research method with a semi-structured interview, which invited an end-stage renal disease patient, and discussed the healing experiences within and outside the hospital premises. This literature further invited patients with chronic benign lower back pain to share their experience during the healing process. According to Smith et al. (2007), lived stories and personal experience were not shared in quantitative and experimental research methods, such as questionnaire and survey. Therefore, IPA (Smith et al. 1997) provided beginning opportunities for health science and public health practitioners to enter the inner world of patients and to further enhance needed developments in the research process.

In summary, quantitative research methods have had a long history within the fields of health science and public health. However, within the last two decades, a large number of research studies have supported that qualitative research methodology could be a useful and essential tool for practitioners in understanding the inner world of their patients. Unlike quantitative research studies, qualitative studies provide rich and textual evidence for public health practitioners to enhance the current society and environment for patients and disabled residents to enjoy their rights within the city. Therefore, educating health science and public health practitioners and learners to be respectful to qualitative research methodology is important. 


\section{Applications of IPA in Health Science}

IPA is also an essential research methodology that can explore contemporary issues and cover research topics at all social science subjects, particularly in health science and public health education. The following sub-sections provide several health science and nursing education studies as examples for the applications of IPA.

\subsection{Employing IPA to Understand the Views on Respect of Student Nurses}

A study conducted by Chapman and Clucas (2014) examined the understanding of the respect that student nurses have for their patients, how to exercise respect in the clinical environment, and how to show respect in front of their patients. The purpose of this study is to provide an effective recommendation to reform and develop overall nursing education in the United Kingdom from the perspectives of student nurses.

The study examined and interviewed eight participants from four different education and practice sites in the United Kingdom. The study outlined three major themes, including 1) the complexity of respect, 2) conflict between attitudes, and 3) other barriers to learning respect in practice. The study discovered that student nurses believed that respect cannot be explained distinctively through conversations and languages because respect is expressed through behaviors toward patients. Some expressed that helping patients to change clothing is one of the respectful behaviors shown by them. In addition, some believed that providing essential care is a way to show respect.

Within the study, the researchers conducted a large number of interviews with the participants to first collect personal communication, feeling, and thinking from frontline student nurses. Unlike large-scale survey and questionnaire studies, this type of IPA allowed researchers, student nurses, nursing educators, policy makers, patients, and the general society to understand the perspectives and behaviors within the field of health care.

By contrast, within the conversations and textual transcripts from participants, curriculum developers can reform and redesign the current nursing education curriculum and instruction based on contemporary needs and demands from the frontline healthcare providers. Fields of healthcare and public health change rapidly because of the complex illness and crisis in the society. Thus, nursing educators must benefit from lived stories and narration from someone who currently works in a particular situation.

\subsubsection{Discussion of Questions during the In-depth Interview}

The key elements in collecting meaningful interview through in-depth interviews are the interview questions. IPA tends to collect information on lived stories, personal perspectives, background experiences, and inner world understanding from the participants. Therefore, the one-on-one, face-to-face, and semi-structured interview section could be the appropriate arrangement for individuals to share their sensitive information in a private environment. Some scholars argued that focus on group could be employed in IPA study (Tomkins \& Eatough, 2010). However, as IPA researchers seek to understand the inner world of individuals and the sense-making process, some sensitive information cannot be expressed within a large group 
and community. Therefore, in-depth interview within a private environment would be the most appropriate way to collect meaningful information.

\subsection{Employing IPA to Understand the Transition to Motherhood in an Organizational Context}

Another study conducted by Millward (2006) examined the life transition of a group of women, which included a mother, a housewife, and an office worker. This study indicated that within the Western cultural society, how to work as a good mother and good wife is a concern in many contemporary families. Before the mid-20th century, most married women stayed at home. However, as women's rights and the general perspectives from the society have been reformed and developed, a large number of married women continued to work during and after pregnancy. Furthermore, the current society has argued that women should stay at home or return to work after a reasonable amount of time after pregnancy.

Within this qualitative IPA study, the researcher did not establish any types of hypothesis and quantitative-oriented questions. The purpose of this study was to understand how eight females make sense of their experiences, particularly the transition to motherhood. Moreover, the researcher aimed to understand how females "make sense of their maternity experience from becoming pregnant, through a period of leave and then return to work in an organizational context" (Millward, 2006, p. 318). To answer such feeling, understanding, and behavioral-oriented questions, only qualitative research method with a direction of IPA could be appropriate.

The research finding indicated two themes: 1) changes in identity and 2) changed psychological contracts. The research discovered that women are usually engaged with identity difficulties with consequent psychological contracts. First, from the in-depth interviews with the guidance of IPA methodology, the researcher was able to capture how participants make sense of their pre-leave period, the feeling of being systematically excluded, and the complexities of legal problems. In addition, the insecurity issue regarding their employment was raised by most of the participants. By contrast, the study indicated that the "feeling of exclusion during pregnancy and efforts to prove performance-worth all over again on their return" (p. 327) could be one of the difficulties during the transition to motherhood.

Both outcomes from the IPA research provided a broad picture of the understanding and sense-making process of females transitioning to motherhood concerning their employment status. Such rich and in-depth information may not be captured from a large scale of questionnaire and survey studies. Some may argue that a large size of phenomenological analysis with 30 participants may also capture similar results. However, participants may not be willing to provide all information because of privacy issues and difficulties. In this connection, IPA researchers are able to focus on to these minor emotions to discover facts and information behind the conversation. IPA highly recommends that researchers also capture the facial expressions and minor behaviors of the participants. Thus, a small number of research groups should be more appropriate for the above research.

\section{Conclusion}

In summary, this study briefly discussed the applications of IPA within the field of health 
science and public health. From the past decades, a large number of scientific studies tend to employ quantitative research methodology as the primary data collection procedure. However, some psychological issues, mental health problems, public health education, nursing education, and patient behavioral developments were not captured properly by quantitative research method. Therefore, to capture meaningful information and potential ideas for health development, scholars and practitioners from the above academic fields should keep an open mind to various types of methodologies. As Smith et al. (2009) suggested, the expansions of qualitative research methodologies and IPA will be employed in health science and public health research studies in the coming decades, it is expected to see various types of qualitative research studies in this particular field in order to capture patients' psychological opinions and expressions in the soon future.

\section{Acknowledgement}

None

\section{References}

Benoliel, J.Q. (1984). Advancing nursing science: Qualitative approaches. Western Journal of Nursing Research, 6(3), 1-8. https://doi.org/10.1177/019394598400600306

Bryman, A. (1984). The debate about quantitative and qualitative research: A question of method or epistemology. The British Journal of Sociology, 35(1), 75-92. https://doi.org/10.2307/590553

Carr, L. T. (1994). The strengths and weaknesses of quantitative and qualitative research: What method for nursing. Journal of Advanced Nursing, 20(4), 716-721. https://doi.org/10.1046/j.1365-2648.1994.20040716.x

Chapman, H. M., \& Clucas, C. (2014). Student nurses' views on respect toward service users: An interpretative phenomenological study. Nurse Education Today, 34(3), 474-479. https://doi.org/10.1016/j.nedt.2013.05.012

Cormack, D. F. (1991). The research process in nursing (2nd ed.). Oxford: Blackwell Scientific.

Corner, J. (1991). In search of more complete answers to research question: Quantitative versus qualitative research methods is there a way forward? Journal of Advanced Nursing, 16(3), 718-727. https://doi.org/10.1111/j.1365-2648.1991.tb01730.x

Creswell, J. W. (2007). Educational research: Planning, conducting, and evaluating quantitative and qualitative research (4th ed.). New Delhi: PHI Learning Private Limited.

Dos Santos, L. M. (2016). Relationship between turnover rate and job satisfaction of foreign language teachers in Macau. Journal of Educational Developmental Psychology, 6(2), 125-134. https://doi.org/10.5539/jedp.v6n2p125

Griffiths, M., Schweitzer, R., \& Yates, P. (2011). Childhood experiences of cancer: An interpretative phenomenological analysis approach. Journal of Pediatric Oncology Nursing, 
28(2), 83-92. https://doi.org/10.1177/1043454210377902

Melia, K. M. (1982). "Tell it as it is" Qualitative methodology and nursing research: understanding the student nurse' world. Journal of Advanced Nursing, 7(4), 327-335. https://doi.org/10.1111/j.1365-2648.1982.tb00248.x

Millward, L. J. (2006). The transition to motherhood in an organizational context: An interpretative phenomenological analysis. Journal of Occupational and Organizational Psychology, 79,(3), 315-333. https://doi.org/10.1348/096317906X110322

Morse, J. M. (1994). Designing funded qualitative research. In Denizin, N.K. \& Lincoln, Y.S. Handbook of qualitative research (2nd ed.). Thousand Oaks: Sage.

Smith, J. A., Flowers, P., \& Larkin, M. (2009). Interpretative phenomenological analysis: Theory, method and research. London: Sage.

Smith, J. A., Flowers, P., \& Osborn. (1997). Interpretative phenomenological analysis and the psychology of health and illness. In L. Yardley (Eds)., Material discourses of health and illness. London: Routledge.

Smith, J. A., Harre, R., \& Van Langenhove, L. (1995). Idiography and the case study. In J. A. Smith, R. Harre \& L. Van Langenhove (Eds)., Rethinking Psychology. London: Sage.

Smith, J. A., \& Osborn, M. (2003). Interpretative phenomenological analysis. In J. A. Smith (Ed.), Qualitative psychology: A practical guide to research methods. London: Sage.

Symeonides, R., \& Childs, C. (2015). The personal experience of online learning: An interpretative phenomenological analysis. Computers in Human Behavior, 51(A), 539-545.

Tomkins, L., \& Eatough, V. (2010). Reflecting on the use of IPA with focus group: Pitfalls and potentials. Qualitative research in psychology, 7(3), 244-262. https://doi.org/10.1080/1478088090312149

\section{Copyright Disclaimer}

Copyright for this article is retained by the author(s), with first publication rights granted to the journal.

This is an open-access article distributed under the terms and conditions of the Creative Commons Attribution license (http://creativecommons.org/licenses/by/4.0/). 